\title{
Molecular Mechanisms in the Process of Re-epithelization in Wound Healing and the Action of Honey in Keratinocytes
}

\author{
Mecanismos Moleculares en el Proceso de Re-epitelización en \\ Cicatrización de Heridas y la Acción de la Miel en Queratinocitos
}

Mariela Muñoz ${ }^{1,2,3}$; Bélgica Vásquez ${ }^{4} \&$ Mariano del Sol $^{1,2}$

\begin{abstract}
MUÑOZ, M.; VÁSQUEZ, B. \& DEL SOL, M. Molecular mechanisms in the process of re-epithelization in wound healing and the action of honey in keratinocytes. Int. J. Morphol., 38(6):1700-1706, 2020.

SUMMARY: The treatment of chronic wounds has become a public health issue in recent years mainly due to comorbidities associated with an older population and bacterial resistance. Honey has emerged as an alternative treatment for chronic wounds but lack of knowledge of its mechanism of actionin the treated tissue and low quality of evidence in clinical triads has distanced the medical community from honey as a possible treatment. One of the main processes that is altered in chronic wounds is re-epithelialization mediated by keratinocytes, where proliferation and migration processes are altered. Markers of proliferation, migration and activation of keratinocytes, such as adhesion molecules, growth factors, membrane receptors, signal translating proteins, transcription factors, microRNAs, among others are deregulated in this process. In general, honeys from different floral origins have a positive effect on markers of proliferation and migration in keratinocytes. In conclusion there are still few studies that focus on the molecular action of honey in keratinocytes and fail to report details on the honey used not allowing to achieve the same results.
\end{abstract}

KEY WORDS: Wound healing; Re-epithelialization; Keratinocytes; Honey.

\section{INTRODUCTION}

The treatment of chronic wounds $(\mathrm{CW})$ has a great impact on public health since the evolution of these wounds is slow and dizzying, along with the increase in bacterial resistance, has led the medical community to seek alternative therapies in the treatment of these wounds. Any wound has the ability to heal successfully or evolve to $\mathrm{CW}$, depending on the associated comorbidities, such as diabetes mellitus, immobilization, postoperative infection, among others. The scientific community has put its interest in honey as a treatment for $\mathrm{CW}$ since the healing properties of honey for the treatment of wounds have been known since antiquity, this knowledge was not always accompanied by quality research on the properties of honey, so it can not be guaranteed that the effect of the product will be replicable over time, which has caused resistance in the medical community for its use. A systematic review, which included 10 triads of patients with $\mathrm{CW}$, the authors stated that it is difficult to draw general conclusions about the effects of honey as a topical treatment for wounds due to the heterogeneous nature of the patients and parameters studied, in addition to the low specification of the honey used. The authors comment on the low quality of the evidence (Jull et al., 2015).

Histologically, CW are characterized by hyperproliferative and non-migratory epidermis, permanent inflammation, bacterial infection and presence of biofilm, decreased of angiogenesis and remodeling of the extracellular matrix (ECM) and fibrosis. A variety of cells are involved in this process, platelets, neutrophils, fibroblasts, myofibroblasts, keratinocytes, endothelial cells and macrophages, however, molecular mechanisms involved in persistence of chronic wounds are poorly understood. One mechanisms described being dysregulation of metalloproteinases (MMP) and their inhibitors (Eming et al., 2014).

Scientific evidence has argued in favor of ability of honey to interact with the complex cellular and molecular

\footnotetext{
${ }^{1}$ Center of Excellence in Morphological and Surgical Studies, Universidad de La Frontera, Temuco, Chile.

${ }^{2}$ Becario CONICYT-PCHA/Doctorado Nacional/2017 21170755

${ }^{3}$ Doctorate in Morphological Sciences, Universidad de La Frontera, Temuco, Chile.

${ }^{4}$ Universidad de Tarapacá, Arica, Chile.

Financing: Universidad de La Frontera, Project DIUFRO DI18-0082
} 
machinery to carry out wound healing (Schencke et al., 2013). However, lack of information on quality and categorization of honey as treatment in wounds, together with lack of knowledge of molecular mechanisms involved in the process, make it difficult to reproduce the results to ensure their therapeutic effect.

The healing process is divided in 3 stages that overlap, inflammation, proliferation and remodeling, involving different cell types, cytokines and growth factors at each stage. In the inflammatory stage, immune system cells such as neutrophils, monocytes-macrophages, lymphocytes and platelets are protagonists, in the proliferative stage, keratinocytes, fibroblasts and endothelial cells are important, macrophages still present, and in the remodeling stage there is presence of fibroblasts, myofibroblasts and macrophages (Gonzalez et al., 2016; Sorg et al., 2017). During the proliferative stage a fundamental event occurs so that the healing process is successful, the keratinocytes of the wound margins proliferate, migrate and differentiate to close the wound and restore the integrity of the epidermis by a process called re-epithelialization (Pastar et al., 2014).

One of the signs of evolution to $\mathrm{CW}$ is failure in process of re-epithelialization, a process that is studied in vivo and in vitro models of acute wounds since there are no animal or in vitro models to study chronic wounds but it suggests that the mechanisms involved in reepithelialization process would will be similar (Eming et $a l$.). Thus, the objective of study was to describe molecular mechanisms in keratinocytes involved in reepithelialization process and molecular effects of honey on these cells.

\section{Molecular mechanisms in wound healing in keratinocytes}

During healing process there is a high number of molecules and cells involved, keratinocytes play an important role in homeostasis of the skin through proliferation and differentiation that allows during the first stage of healing restore the integrity of skin by a process called re-epithelization, where keratinocytes from unhealed edges of wound, proliferate, migrate and differentiate to close the wound (Singer \& Clark, 1999). Although molecular mechanisms involved in this process are not completely known in recent years, progress has been made in understanding molecules involved in proliferation and migration of keratinocytes.

A dominant negative mutant for expression of Rac1 in keratinocytes showed a significant delay in reepithelialization compared to wild type mouse, concluding that inhibition of Rac1 decreased proliferation, migration of keratinocytes and pERK (Tscharntke et al., 2007). Stojadinovic et al. (2008) wanted to verify the idea that failure in processes of activation and differentiation of keratinocytes would have a role in the generation of $\mathrm{CW}$. They studied expression profile by microarray (Affymetrix) of skin from unhealed edge of venous ulcers and healthy skin, finding 1557 differentially regulated genes. There was increased expression in markers of early activation of keratinocytes, keratins 6,16 and 17. They observed an imbalance in genes related to cell cycle with a decrease in expression of retinoblastoma proteins family $(\mathrm{Rb}, \mathrm{p} 107$ and p130 ) and increase expression of CDC2, cyclin B1, cyclin $\mathrm{D} 2$, cyclin $\mathrm{A} 2$, cyclin $\mathrm{F}$ and cyclin $\mathrm{M} 4$, promoting increase of the complexes CDC2 / cyclin B1 and CDC2 / cyclin A2 which promote transitions $\mathrm{G} 1 / \mathrm{S}$ and $\mathrm{G} 2$ / M in cell cycle, added to the decrease in the expression of CHES1 and WEE1, both regulatory points of cell cycle, the authors observed expression profile of genes that promote hyperproliferative phenotype. There was a decrease in expression of K1 and K10, early markers, and of filaggrin and trichohialin, late markers, of keratinocytes. They also observed decrease in expression of genes from tight junctions, TJ protein 3 , spectrin 1 , InaD type protein, Claudin 5 and 8 , occludin and the components of the polarity complexes PARD and CDC42. The authors observed dysregulation of genes encoding desmosromasomal cadherin proteins, increased expression of desmocolin 2 and desmoglein 3 and decreased expression of desmocolin 3 and desmoglein 2, also desmoplakin and plakophilin 2 decreased their expression. The authors state that keratinocytes in venous ulcers initiate process of differentiation but fail to successfully complete this process and prevent formation of an epidermal barrier.

In order for an efficient re-epithelialization process, desmosomal adhesion complexes must be modified so that migration of keratinocytes from the unhealed edges of wound occurs first and subsequent epidermal restructuring occurs. The desmosomes in epidermis of adult mice showed a strongly adhesive "Hyperadhesive" $\mathrm{Ca}^{++}$independent phenotype and desmosomal adhesion after a wound becomes $\mathrm{Ca}^{++}$dependent and less adhesive, who regulates, in part this, is PKC $\alpha$. The inhibition of PKC $\alpha$ significantly decreases wound closure in vitro and re-epithelialization in vivo, and its increase, accelerates re-epithelialization process. Decrease in the "hyperadhesive" phenotype of desmosomes was observed in presence of inhibitor and in knockout mouse for PKC $\alpha$, demonstrating importance of $\mathrm{PKC} \alpha$ in regulation of desmosomal adhesion. In biopsies of unhealed edges of $\mathrm{CW}$, abundance of "hyperadhesive" desmosome phenotype was observed, unlike acute wounds, which would explain decrease in epidermal migration (Thomason et al., 2012; Wallis et al., 2000). 
Connective tissue growth factor $(\mathrm{CCN} 2)$ regulates migration of keratinocytes by activation of Ras-MEK-ERK signal translation pathway, belonging to MAPKs family, which would allow closure of wound through union from keratinocytes to fibronectin throug Integrina receptor a5b1 and activation of local adhesion kinase (FAK). Transforming growth factor $\beta$ (TGF $\beta$ ) stimulates expression of CCN2 in hyperproliferative keratinocytes (Kiwanuka et al., 2013a; Kiwanuka et al., 2013b). Overexpression of Src accelerates wound healing by promoting migration of keratinocytes and mechanism involved would be through increase in expression of MMP- 2 via signaling path ERK $1 / 2$ (Wu et al., 2016).

Transcription factor FOXO1 is involved in regulation ECM. In keratinocytes and mice with FOXO1 deletion there was a decrease in the formation of the collagen matrix, fibroblasts and myofibroblasts, and a decrease in the expression of TGF $\beta$ and $\mathrm{CCN} 2$ was also seen. Activation of the transcription factor FOXO1 would induce release of TGF $\beta$ by keratinocytes to stimulate process of reepithelization and remodeling of ECM by increasing expression of $\mathrm{CCN} 2$ that stimulates fibroblasts, myofibroblasts and cells that express mesenchymal cell markers (Ponugoti et al., 2013; Zhang et al., 2017).

\section{MicroRNAs involved in the re-epithelialization process expressed in keratinocytes}

MicroRNAs are a new focus of study in process of wound healing. miR-21 attenuates migration of keratinocytes, and in cells that overexpress it there is a decrease in expression of inhibitor of metalloproteinase 3 (TIMP3) and protein for the induction of metastasis and invasion of T-lymphoma (TIAM1) (Yang et al., 2011). miR31 increased its expression in keratinocytes of unhealed edges of wound during inflammatory and proliferative phase and positively influenced proliferation and migration of these. Bioinformatic analysis showed that epithelial membrane protein (EMP-1) was a target of miR-31 and overexpression of it, decreased expression of EMP-1, increased expression of TGF $\beta 1$ and TGF $\beta 2$ and proliferation of keratinocytes ( $\mathrm{Li}$ et al., 2015a). Overexpression of miR155 resulted in acceleration of healing process and reepithelialization, improving migration of keratinocytes, with overexpression of MMP-2 and decreased expression of its inhibitor TIMP-1 (Yang et al., 2017). Li et al (2015b) confirmed increase of miR-31 and miR-155 by analysis of a total of 754 microRNAs expressed in skin and added to miR32 as a microRNA not overexpressed in keratinocytes in response to TGF $\beta 1$ and TGF $\beta 2$ during wound healing process, miR-32 inhibits NF-kB signaling pathway and promotes proliferation of keratinocytes through EGFR, ERK and STAT3 signaling pathways and decrease expression impairs healing process due to sustained inflammation and deficiency in proliferation of keratinocytes. miR-483-3p increases expression and decreasing the proliferation of keratinocytes at end of re-epithelialization (Bertero et al., 2011).

\section{Effects of honey at the molecular level in the process of re-epithelialization during wound healing}

Proliferation and migration of keratinocytes is one of pillars of the re-epithelialization process being crucial in wound healing, so knowledge of effect of honey on molecular mechanisms involved in these functions is an important study objective.

As Figure 1 shows, honey induces an increase in the expression of IL-1b, TNFa and TGFb from keratinocytes (Majtan et al., 2010). These three molecules are important in the keratinocyte activation cycle: IL-1b diminishes the expression of the basal keratins K14 and K19, while TNFa keeps the keratinocytes in an activated state (Freedberg et al., 2001), promoting the expression of keratin K6. After any skin wound, the keratinocytes at the margin of the wound express the keratins K6, K16 and K17 these are markers of activated keratinocytes, which are hyperproliferative and are found in the suprabasal layers of the epidermis, providing the necessary mechanical characteristics for the migration process (Moll et al., 2008). A study in the keratinocytes of double mutant mice for K6a and K6b showed that the absence of this keratin increased the epithelization potential, because the migratory capacity of the keratinocytes increased (Wong \& Coulombe, 2003). Likewise, over-expression of Src accelerates wound healing by promoting keratinocyte migration, and the mechanism involved would be through increased MMP-2 expression by the signalling pathway ERK1/2 (Wu, 2016). Rotty and col postulate that K6 expression and its union with Src protein kinase is a mechanism to regulate the activity of this protein, which increases in the absence of K6 (Rotty \& Coulombe, 2012). Thus increased K6 expression would restrain the action of Src and therefore the expression of MMP-2, which is necessary for successful wound healing. There is evidence that honey increases MMP-2 and ERK1/2 expression (Ranzato et al., 2012), so the mechanism may function through Src expression; in this case K6 expression would act as a regulation point to restrain the action of MMP-2. This molecule is necessary in the first instance for keratinocyte migration, but its action needs to be restrained in the following stage of cicatrization for this to be successful.

Ranzato et al. studied effect of three types monofloral honeys, Acacia Honey (Robinia pseudacacia), 




Fig. 1. Molecular action mechanisms of honey in keratinocytes. The molecular action mechanisms of honey in keratinocytes are shown with scientific evidence (black arrow), and hypotheses of the possible molecular action of honey in keratinocytes (dotted blue arrow). The red lines show the inhibition mechanism.

Buckwheat Honey (genus Fagopyrum) and Manuka Honey (New Zealand teatree, Leptospermum scoparium) for several molecular markers involved in wound healing. All honeys showed significant wound closure (Scratch test) but there were significant differences in molecular markers evaluated. Decrease in wound closure was observed in presence of BAPTA, inhibitor of intracellular $\mathrm{Ca}^{++}$. They observed increase in expression of MMP-9 with all honeys used, MMP-3 was slightly elevated in cells treated with Manuka honey while MMP-10 and 13 and TIMP-4 decreased their expression in cells treated with acacia honey and buckwheat respectively. All honeys activated CDK2, cyclin-dependent kinase involved in the G1-S transition and proliferation of keratinocytes, and local adhesion kinase (FAK) and rasGAP SH3 binding protein 1, both involved in cellular locomotion. Acacia and Buckwheat honey increased expression of vimentin (mesenchymal phenotype marker) and decreased expression of keratin 14 and 19 (epithelial phenotype marker). Honey increases expression of syndecan-4, an important protein involved in cell adhesion and migration which is present in adhesion foci (Ranzato et al.); syndecan-4 in turn activates PKC $\alpha$ (Lim, et al., 2003).

The keratins $\mathrm{K} 6 / \mathrm{K} 17$, expressed in activated keratinocytes, can increase $\mathrm{PKC} \alpha$ expression, also promoting loss of the desmosome junction (Loschke et al., 2016). Although it has been shown that K6 expression is associated with changes in the keratinocytes which promote the formation of its activated phenotype, to date there are no studies which show directly whether honey increases expression of this particular keratin, or the keratin profile in general.

Multifloral honey combined with alginate matrix (HAF) showed faster wound closure compared to control and alginate matrix alone. At 48 hours of Scratch assay only HAF produced total closure of wound. Expression of Ki67 (cell proliferation marker) was high in group treated with $\mathrm{HAF}$ at $12 \mathrm{~h}$ and at $24 \mathrm{~h}$ they lowered their level, which agrees with decrease in proliferation process and initiation of re-epithelialization. Decrease of Ki67 and upregulation of p53 and E-cadherin at $24 \mathrm{~h}$ indicates reduction of epithelial cell proliferation and initiation of cell cell adhesion. The authors conclude that presented evidence shows that presence of honey in alginate matrix improves molecular events associated with re-epithelization process (Barui et al., 2013).

Chaudhary et al. (2015) used honey of Indian origin, without specifying floral origin, on $\mathrm{HaCaT}$ cells and observed that a dilution of $0.1 \%$ of honey increased expression of p63, indicative of cell proliferation, which was associated with a wound closure more rapid, together with a cytoplasmic expression of E-cadherin and $\beta$-catenin suggesting migration of cells during wound closure.

An uncicatrized wound is an environment rich in reactive oxygen species, which are deleterious for the cells; however, these molecules, especially hydrogen peroxide $\left(\mathrm{H}_{2} \mathrm{O}_{2}\right)$, can act as intermediaries in the intracellular signal transduction pathways. Honey increases the expression of 
Aquaporin 3 (APQ3), a transmembrane channel present in keratinocytes which can transport water, glycerol and other small molecules, including $\mathrm{H}_{2} \mathrm{O}_{2}$ (Hara-Chikuma et al., 2015). When AQP3 expression increases, the entry of $\mathrm{H}_{2} \mathrm{O}_{2}$ into the cell also increases, activating transient receptor potential melastatin 2 (TRM2) and Orai1 channels, inducing calcium entry with a consequent increase in intracellular $\mathrm{Ca}^{++}$ (Martinotii et al., 2019). Keratinocytes express the enzyme NADPH oxidase (Nox) types 1 and 2; Nox2 induces the formation of extracellular $\mathrm{H}_{2} \mathrm{O}_{2}$ by stimulating $\mathrm{TNF} \alpha$, which enters the cell through AQP3 (Hara-Chikuna et al.). It is known that the $\mathrm{H}_{2} \mathrm{O}_{2}$ present in honey is due to the action of the glucose oxydase enzyme on the glucose, generating $\mathrm{H}_{2} \mathrm{O}_{2}$ and glucoronic acid as a product, on the other hand, the keratinocytes are also capable of producing extracellular $\mathrm{H}_{2} \mathrm{O}_{2}$ in the presence of TNF $\alpha$. Thus we can hypothesise that the contact of honey with keratinocytes during cicatrization could increase extracellular $\mathrm{H}_{2} \mathrm{O}_{2}$ levels by increasing expression of the enzyme NADPH oxydase 2 through stimulation of TNF $\alpha$. So honey has two mechanisms for enhance intracellular $\mathrm{H}_{2} \mathrm{O}_{2}$, by increasing AQP3 expression and TNF $\alpha$ expression. Increased AQP3 expression promotes cell proliferation and release of TNF $\alpha$ by the notch signalling pathway (Guo et al., 2013), keeping the keratinocytes in an activated, undifferentiated state. In contrast, the silencing of AQP3 increases levels of activated notch significantly, also increasing the expression of $\mathrm{K} 1$, a differentiation marker; this shows that increased AQP3 expression promotes an undifferentiated proliferative phenotype (Guo et al.), which is necessary in the first stage of re-epithelization.

\section{DISCUSSION}

Molecular actors involved in wound healing are almost innumerable and involve a variety of molecules and cells at different stages of healing process, resulting in a complex network of underlying mechanisms. Molecules related to function that keratinocytes have in this process are also quite and not fully understood, including growth factors, cytokines, membrane receptors, adhesion molecules, signal translating proteins and microRNAs.

Stojadinovic et al. and Thomason et al. agree that molecules involved in cell-cell adhesion, such as desmosomes, would play an important role in migration process of keratinocytes and subsequent restructuring of epidermis as a barrier, failure of these mechanisms being a possible cause of chronic wounds.

The studies focused on microRNAs (Li et al., 2015a;
Yang et al., 2011, 2017) agree that increase in the expression of TGF $\beta$ regulates expression of microRNAs and promotes migration of keratinocytes, an essential process for a normal wound healing.

During re-epithelialization process, keratinocytes must detach from basement membrane, secreting metalloproteinases (MMPs), including MMP-9, which degrades type IV collagen and elastin. Majtan et al. and Ranzato et al. observed an effect of honey on this type of molecules and their inhibitors.

Honey has been studied as a whole and also isolated and purified proteins of the same honey, not finding a significant difference in effects seen. Majtan et al. found no significant difference in molecular markers studied when using acacia honey or purified protein of this MRJP1.

In reviewed studies (Barui et al.; Chaudhary et al.; Majtan et al.; Ranzato et al.) information on type of honey used was very basic, referring only if it is mono or multifloral, not inform pollen percentage in the case of monofloral honey, which could be a relevant data in case of wanting to reproduce the results, even in the case of the study carried out by the Chaudary et al., they only comment that the honeys used are from India and that according to physical and chemical analysis, honey A was chosen to carry out the study. Only when Manuka honey was used was information "Unique Manuka Factor" (UMF) index given that accounts for a type of categorization of this type of honey. Ranzato et al. mention the importance of the botanical origin of honey but in their study they do not specify characteristics of the honeys used.

Although Ranzato et al. carried out an extensive study in relation to molecules involved in re-epithelialization process of keratinocytes, their study was rather descriptive without postulating any mechanisms of honey action.

There were differences in controls used in the Scratch trial to evaluate cell migration, some authors used controls that promoted wound closure as a platelet lysate (Ranzato et $a l$.), while others used a control without any additive to promote migration or wound closure (Chaudhary et al.), and could vary the perception of wound closure. A positive aspect derived from the present review is that most of the studies carried out to analyze the effect of honey on keratinocytes were performed on the $\mathrm{HaCaT}$ immortalized human skin keratinocyte cell line, which provides an important point of comparison between the studies (Barui et al.; Chaudhary et al.; Ranzato et al.), however, to evaluate honey as a possible treatment for chronic wounds, an animal model is needed that resembles the characteristics of a chronic wound (Eming et al.). 
In conclusion there are still few studies that focus on the molecular action of honey in keratinocytes and fail to report details on the honey used not allowing to achieve the same results. Thus the molecular mechanisms of the action of honey in keratinocytes during re-epithelization are associated principally with the first stage of this process, when keratinocytes must migrate and remain in an activated state.

MUÑOZ, M.; VÁSQUEZ, B. \& DEL SOL, M. Mecanismos moleculares en el proceso de re-epitelización en la cicatrización de heridas y la acción de la miel en queratinocitos. Int. J. Morphol., 38(6):1700-1706, 2020.

RESUMEN: El tratamiento de heridas crónicas (HC) se ha vuelto un tema de salud pública en los últimos años, principalmente debido a comorbilidades asociadas a una población de mayor edad y a la resistencia bacteriana. La miel ha surgido como un tratamiento alternativo para $\mathrm{HC}$ pero la falta de conocimiento de su mecanismo de acción en el tejido tratado y de la baja calidad de la evidencia en triadas clínicas, ha distanciado a la comunidad médica de la miel como posible tratamiento. Uno de los principales procesos que se ve alterado en las $\mathrm{HC}$ es la re-epitelización mediada por queratinocitos, donde se ven alterados los procesos de proliferación y migración. Marcadores de proliferación, migración y activación de queratinocitos, como moléculas de adhesión, factores de crecimiento, receptores de membrana, proteínas traductores de señales, factores de transcripción, microARNs, entre otras, se ven desreguladas en éste proceso. De manera general las mieles de diferentes orígenes florales tienen un efecto positivo en marcadores de proliferación y migración en queratinocitos. En conclusión aún existen pocos estudios que se enfoquen en la acción molecular de la miel en queratinocitos y los pocos que existen fallan en la entrega de información en relación a la miel utilizada que pueda hacer reproducibles los resultados.

PALABRAS CLAVES: Cicatrización; Re-epitelización; Queratinocitos; Miel.

\section{REFERENCIAS}

Barui, A.; Mandal, N.; Majumder, S.; Das, R.; Sengupta, S.; Banerjee, P.; Ray, A.; RoyChaudhuri, C. \& Chatterjee, J. Assessment of molecular events during in vitro re-epithelialization under honey-alginatematrix ambience. Mater. Sci. Eng. C. Mater. Biol. Appl., 33(6):3418-25, 2013.

Bertero, T.; Gastaldi, C.; Bourget-Ponzio, I.; Imbert, V.; Loubat, A.; Selva, E.; Busca, R.; Mari, B.; Hofman, P.; Barbry, P.; Meneguzzi, G.; Ponzio, G. \& Rezzonico, R. miR-483-3p controls proliferation in wounded epitelial cells. FASEB J., 25(9):3092-105, 2011.

Chaudhary, A.; Bag, S.; Mandal, M.; Krishna Karri, S. P.; Barui, A.; Rajput, M.; Banerjee, P.; Sheet, D. \& Chatterjee, J. Modulating prime molecular expressions and in vitro wound healing rate in keratinocyte $(\mathrm{HaCaT})$ population under characteristic honey dilutions. $J$. Ethnopharmacol., 166:211-9, 2015.

Eming, S. A.; Martin, P. \& Tomic-Canic, M. Wound repair and regeneration: mechanisms, signaling and translation. Sci. Transl. Med., 6:265sr6-265sr6, 2014.
Freedberg, I. M.; Tomic-Canic, M.; Komine, M. \& Blummenberg, M. Keratins and the keratinocyte activation cycle. J. Invest. Dermatol 116(5):633-40, 2001

Gonzalez, A. C.; Costa, T. F.; Andrade, Z. A. \& Medrado, A. R. Wound healing - A literature review. An. Bras. Dermatol., 91(5):614-20, 2016.

Guo, L.; Chen, H.; Li, Y.; Zhou, Q. \& Sui, Y. An aquaporin 3-notch1 axis in keratinocyte differentiation and inflammation. PLoS One, 8(11): e80179, 2013.

Hara-Chikuma, M.; Satooka, H.; Watanabe, S.; Honda, T.; Miyachi, Y.; Watanabe, T. \& Verkman, A.S. Aquaporin-3 mediated hydrogen peroxide transport is required for NF-kB signalling in keratinocytes and development of psoriasis. Nat. Commun., 6:7454, 2015.

Lim, S. T.; Longley, R. L.; Couchman, J. R. \& Woods, A. Direct binding of syndecan-4 cytoplasmatic domain in to the catalytic domain of protein kinase $\mathrm{C}$ alpha (PKC alpha) increases focal adhesion localization of PCK alpha. J. Biol. Chem., 278(16):13795-802, 2003.

Loschke, F.; Homberg, M. \& Magin, T. M. Keratin isotypes control desmonome stability and dynamics through $\mathrm{PKC} \alpha$. J. Invest. Dermatol.,136(1):202-13, 2016.

Jull, A. B.; Cullum, N.; Dumville, J. C.; Westby, M. J.; Deshpande, S. \& Walker, N. Honey as a topical treatment for wounds. Cochrane Database Syst. Rev., 6(3):CD005083, 2015.

Kiwanuka, E.; Hackl, F.; Caterson, E. J.; Nowinski, D.; Junker, J. P.; Gerdin, B. \& Eriksson, E. CCN2 is transiently expressed by keratinocytes during re-epithelialization and regulates keratinocyte migration in vitro by the ras-MEK-ERK signaling pathway. J. Surg. Res., 185(2):e109-19, $2013 \mathrm{a}$.

Kiwanuka, E.; Andersson, L.; Caterson, E. J.; Junker, J. P.; Gerdin, B. \& Eriksson E. CCN2 promotes keratinocyte adhesion and migration via integrin a5b1. Exp. Cell Res., 319(19):2938-46, $2013 b$.

Li, D.; Li, X. I.; Wang, A.; Meisgen, F.; Pivarcsi, A.; Sonkoly, E.; Ståhle, M.; Landén, N. X. MicroRNA-31 promotes skin wound healing by enhancing keratinocyte proliferation and migration. J. Invest. Dermatol., 135(6):1676-85, 2015a.

Li, D.; Wang, A.; Liu, X.; Meisgen, F.; Grünler, J.; Botusan, I. R.; Narayanan, S.; Erikci, E.; Li, X.; Blomqvist, L.; Du, L.; Pivarcsi, A.; Sonkoly, E.; Chowdhury, K.; Catrina, S. B.; Ståhle, M. \& Landén, N. X. MicroRNA-132 enhances transition from inflammation to proliferation during wound healing. J. Clin. Invest., 125(8):3008-26, $2015 \mathrm{~b}$.

Majtan, J.; Kumar, P.; Majtan, T.; Walls, A. F. \& Klaudiny, J. Effect of honey and its major royal jelly protein 1 on cutokine and MMP-9 mRNA transcripts in human keratinocytes. Exp. Dermatol., 19(8):e739, 2010.

Martinotti, S.; Laforenza, U.; Patrone, M.; Moccia, F. \& Ranzato, E. Honeymediated wound healing: $\mathrm{H} 2 \mathrm{O} 2$ Entry through AQP3 determines extracellular Ca+2 influx. Int. J. Mol. Sci., 20(3):764, 2019.

Moll, R.; Divo, M. \& Langbein, L. The human keratins: biology and pathology. Histochem. Cell. Biol., 129(6):705-33, 2008.

Pastar, I.; Stojadinovic, O.; Yin, N. C.; Ramirez, H.; Nusbaum, A. G.; Sawaya, A.; Patel, S. B.; Khalid, L.; Isseroff, R. R. \& Tomic-Canic, M. Epithelialization in Wound Healing: A Comprehensive Review. Adv. Wound Care, 3(7):445-64, 2014.

Ponugoti, B.; Xu, F.; Zhang, C.; Tian, C.; Pacios, S. \& Graves, D. T. FOXO1 promotes wound healing through the up-regulation of TGF-b1 and prevention of oxidative stress. J. Cell Biol., 203(2):327-43, 2013.

Ranzato, E.; Martinotti, S. \& Burlando, B. Epithelial mesenchymal transition traits in honey-driven keratinocyte wound healing: Comparison among different honeys. Wound Repair Regen., 20(5):77885, 2012.

Rotty, J. D. \& Coulombe, P. A. A wound-induced keratin inhibits Src activity during keratinocyte migration and tissue repair. J. Cell Biol. 197(3):3819, 2012.

Schencke, C.; Vasconcellos, A.; Sandoval, C.; Torres, P.; Acevedo, F. \& del Sol, M. Morphometric evaluation of wound healing in burns treated with Ulmo (Eucryphia cordifolia) honey alone and supplemented with ascorbic acid in guinea pig (Cavia porcellus). Burns Trauma, 4:25, 2016. 
Singer, A. J. \& Clark, R. A. Cutaneous wound healing. N. Engl. J., 341(10):738-46, 1999.

Sorg, H.; Tilkorn, D. J.; Hager, S.; Hauser, J.; Mirastschijski, U. Skin wound healing: An update on the current knowledge and concepts. Eur. Surg. Res., 58(1-2):81-94, 2017.

Stojadinovic, O.; Pastar, I.; Vukelic, S.; Mahoney, M. G.; Brennan, D.; Krzyzanowska, A.; Golinko, M.; Brem, H. \& Tomic-Canic, M. Deregulation of keratinocyte differentiation and activation: a hallmark of venous ulcers. J. Cell Mol. Med., 12(6B):2675-90, 2008.

Thomason, H. A.; Cooper, N. H.; Ansell, D. M.; Chiu, M.; Merrit, A. J.; Hardman, M. J. \& Garrod, D. R. Direct evidence that PKCa positively regulates wound re-epithelialization: correlation with changes in desmosomal adhesiveness. J. Pathol., 227(3):346-56, 2012.

Tscharntke, M.; Pofahl, R.; Chrostek-Grashoff, A.; Smyth, N.; Niessen, C.; Niemann, C.; Hartwig, B.; Herzog, V.; Klein, H. W.; Krieg, T.; Brakebusch, C. \& Haase, I. Impaired epidermal wound healing in vivo upon inhibition or deletion of Rac1. J. Cell Sci., 120(Pt 8):148090, 2007

Wallis, S.; Lloyd, S.; Wise, I.; Ireland, G.; Fleming, T. P. \& Garrod D. The alpha isoform of protein kinase $\mathrm{C}$ is involved in signaling the response of desmosomes to wounding in cultured epithelial cells. Mol. Biol. Cell, 11(3):1077-92, 2000.

Wong, P. \& Coulombe, P. A. Loss of keratin 6 (K6) proteins reveals a fuction for intermediate filaments during wound repair. J. Cell Biol., 163(29):327-37, 2003

Wu, X.; Yang, L.; Zheng, Z.; Li, Z.; Shi, J.; Li, Y.; Han, S.; Gao, J.; Tang, C.; Su, L. \& Hu, D. Scr promotes cutaneous wound healing by regulating MMP-2 through the ERK pathway. Int. J. Mol. Med., 37(3):639-48, 2016.

Yang, X.; Wang, J.; Guo, S. L.; Fan, K. J.; Li, J.; Wang, Y. L.; Teng, Y.; Yang, X. miR-21 promotes keratinocyte migrationand reepithelialization during wound healing. Int. J. Biol. Sci., 7(5):685-90, 2011.

Yang, L.; Zheng, Z.; Zhou, Q.; Bai, X.; Fan, L.; Yang, C.; Su, L.; Hu, D. miR-155 promotes cutaneous wound healing through enhanced keratinocytes migration by MMP-2. J. Mol. Histol., 48(2):147-55, 2017.

Zhang, C.; Lim, J.; Liu, J.; Ponugoti, B., Alsadun, S.; Tian, C.; Vafa, R. \& Graves, D. FOXO1 expression in keratinocytes promotes connective tissue healing. Sci. Rep., 7:42834, 2017.
Corresponding author:

Mariela Muñoz

Center of Excellence in Morphological and Surgical Studies Universidad de La Frontera

Temuco

CHILE

Email: mariela.munoz@ufrontera.cl

Received: 16-05-2020

Accepted: 28-07-2020 